\title{
Clinical case of complications of inguinal node metastatic lesion in gastric cancer after surgical treatment
}

\author{
I. I. Shtefanov ${ }^{1}$, A. A. Zhakipova ${ }^{2}$, K. E. Mukhtarova ${ }^{3}$, M. N. Peradze ${ }^{4}$, A. K. Makishev ${ }^{1}$
}

\begin{abstract}
Objective: To study the phenomena of complications of atypical distant lymphangitic metastasis by the example of gastric cancer.

Methods: Within the framework of the study "Hereditary diffuse gastric cancer and measures for its prevention", a clinical group and a control group of patients with the most likely risk of developing this genetic disease were recruited. DNA samples were taken from 119 patients of the main clinical group and the control group. In the course of filling out statistical charts, questioning and examination of patients, cases of distant lymphangitic and hematogenous metastasis were revealed in 7 patients. As diagnostic methods for distant lymphangitic and hematogenous metastasis, we used the results of studies of computed tomography, positron emission tomography combined with computed tomography of the whole body, nuclear magnetic resonance imaging, ultrasound methods, open biopsy and trephine-biopsy of lymph nodes.

Results: Krukenberg's tumors were detected in 2 patients, Virchow's metastases - in 2 patients, metastases in the paraumbilical region - in 2 patients, Schnitzler metastases - in 1 patient, Irish node was detected in 1 of the examined patients. There was also a metastatic lesion of the lymph nodes of inguinal region on the left in 2 patients and one case of metastasis to the right testicle in a patient with true inguinal cryptorchidism. This article reflects one case of metastatic lesion of the inguinal nodes on the left and subsequent complications in the form of lymphostasis and pain syndrome.

Conclusion: According to the classification of distant metastases in case of malignant neoplasms of the stomach, classical cases of metastases of Krukenberg, Virchow, Schnitzler, Sister Mary Joseph, and Irish were revealed. There is atypical metastasis to the inguinal nodes and to the undescended (true inguinal cryptorchidism) right testicle, which does not fall under the generally accepted classification of distant metastases of gastric cancer. Further tactics of treatment in the case of metastatic lesion to the inguinal regions in gastric cancer are not entirely clear, which requires an increase in the study of the amount of these clinical cases.
\end{abstract}

Keywords: Virchow's metastasis, Schnitzler metastasis, Sister Mary Joseph's nodule, Irish node, Krukenberg's tumors

\section{INTRODUCTION}

Gastric cancer (GC) is the third largest mortality in the world. About 980 thousand people fall ill with gastric cancer in the world each year, while the mortality rate is 740 thousand people (according to WHO data from 2014).

In our country, the incidence of stomach cancer ranks fourth after breast cancer, lung cancer and skin cancer. High mortality rates from this malignant neoplasm, which ranks second in the number of deaths, are noted. The number of patients with gastric cancer in the Republic of Kazakhstan in 2017 is 2,737 people, with a death of 1,699 people. The mortality rate from gastric cancer in the Republic of Kazakhstan in 2017 is 9.5 cases per 100.0 thousand of population, the incidence rate is 15.3 cases per 100 thousand of population (according to the annual statistical materials "Indicators of the Oncological Service of the Republic of Kazakhstan"). As can be seen from statistics, the problem of gastric cancer for our country is very relevant. Diagnosis and prevention of gastric cancer are of great importance and require constant improvement according to the achievements of modern science and medicine.

According to the statistics "Indicators of the Oncological Service of the Republic of Kazakhstan", the specific gravity of the IV stage of malignant neoplasms of the stomach by main localizations in 2017 amounted to $18.2 \%$. One of the main indicators determining the prognosis of GC, like most other malignant tumors, is the degree of prevalence of disease at the time of diagnosis. Most often, hematogenous metastasis of GC occurs in the liver, along the portal vein.

\footnotetext{
NJSC "Astana Medical University", Nur-Sultan, Kazakhstan.

2 SMMC on REM "Oncological Center", Nur-Sultan, Kazakhstan.

3 RSE "National Center for Biotechnology" CS MES RK, Nur-Sultan, Kazakhstan.

4 MUS on REM "Pathological Bureau", Nur-Sultan, Kazakhstan.
} Correspondence: I. I. Shtefanov
Assistant of Oncology Department, NJSC "Astana Medical University", Manas street
17, Nur-Sultan, 010000, Kazakhstan.

E-mail: ivan_tern@mail.ru

Received: 5 Jun 2019, Accepted: 3 Dec 2019

(C) 2019 by the authors; licensee Modestum Ltd., UK. This article is an open access article distributed under the terms and conditions of the Creative Commons Attribution License (http://creativecommons.org/licenses/by/4.0/). 
Possible metastases in the lungs and other organs (kidneys, bones, brain, less often in the adrenal glands and pancreas). In the lymphogangitic gastric cancer metastases are found in regional lymph nodes: along the left and right gastric arteries, the right and left gastro-omental, splenic - regional nodes of the first stage of lymph efflux; celiac nodes (second stage of lymph efflux); paraaortic, paracaval and others.

Currently, most of the initially diagnosed patients, which is approximately $65 \%$ of patients diagnosed with gastric cancer, are detected in III - IV stages, because in the initial stages, the disease in most cases is asymptomatic. Such statistics are characteristic of almost all countries of the world, with the exception of South Korea and Japan, where various screening programs are taking place that contribute to the earlier detection of this malignant neoplasm (1).

In $85 \%$ of cases, metastases in the lymph nodes are diagnosed and in $30 \%$ in distant organs. Despite the ongoing drug therapy, the average life expectancy is less than 12 months (2).

Specific forms of lymphangitic metastasis are distinguished: Virchow's metastases (Virchow nodes) - damage to the lymph nodes of the left supraclavicular the area between the legs of the sternocleidomastoid muscle; Schnitzler metastases - in pararectal lymph nodes; Irish nodes - in axillary lymph nodes; Sister Maria Joseph's nodules - in the navel along the round ligament of liver; Krukenberg's tumors - into the ovaries (3).

This clinical example describes metastasis of intestinal gastric cancer in the left inguinal-iliac group of lymph nodes, which is an atypical case and requires oncological alertness during tertiary prophylaxis of patients with this malignant neoplasm.

The priority treatment method for primary disseminated or systemic gastric cancer is the drug. In most cases, it is recommended that systemic chemotherapy be prescribed for locally advanced unresectable and disseminated gastric cancer and esophageal-gastric anastomosis (4). According to the practical recommendations for the medicinal treatment of gastric cancer, surgical removal of the primary tumor and/or metastasectomy in case of initially inoperable locally advanced or disseminated/metastatic GC is not recommended, because this procedure does not increase life expectancy. Some cases of prolonged survival of patients after removal of single metastases in the liver, retroperitoneal lymph nodes, lungs, Krukenberg's tumors have been described (5).

In this particular clinical case, due to concomitant cardiac pathology, only the surgical method was used during the initial treatment and in the subsequent treatment.

\section{CASE STUDY}

\section{Clinical and Demographic Data}

Age: 01.04 .194276 years

Sex: female

Main occupation: pensioner

Ethnicity: Kazakh

Weight: $42 \mathrm{~kg}$

Height: $162 \mathrm{~cm}$

\section{Diagnosis}

Main: Cardioesophageal c-r T4aN3aM0 St IIIC. Condition after an expanded-combined gastrosplenectomy with resection of the lower thoracic esophagus, lymphadenectomy D 2 from 12/12/2017. Process progression. Soft tissue metastases in the lower third of the left thigh, lumbar region on the right, gluteal regions on the left, axillary region on the left. Condition after removal of soft tissue tumors of the left thigh, gluteal region on the left, anterior chest wall from 09/19/2018. Clinical group 4.

Secondary: Arterial hypertension stage 2, risk 4. AV block I degree. Acquired heart disease: aortic stenosis stage 1. Mitral valve insufficiency stage 2. HF Class I (NYHA). Type 2 diabetes mellitus, moderate, subcompensation.

Complaints on admission: Complaints about the presence of formation of the left thigh, left axillary region, lumbar and gluteal regions, persistent pain in the formation region of the left thigh, weakness, weight loss of $20 \mathrm{~kg}$ for a year.

Anamnesis morbi: It has been on the " $D$ " record since 12/05/2017. First contacted a gastroenterologist in September 2017 with complaints of vomiting, epigastric pain, pain behind the sternum. According to the FGDS from 09/26/2017: Ulcer of the cardiac section of stomach. A biopsy was taken, histological conclusion No.5055/47647-47650 from 11/27/2017: low-grade adenocarcinoma. Was consulted by prof. A.K. Makishev, surgical treatment is recommended. 12/12/2017 - under the conditions of MOPC of Astana, an operation was performed on extended gastrosplenectomy 


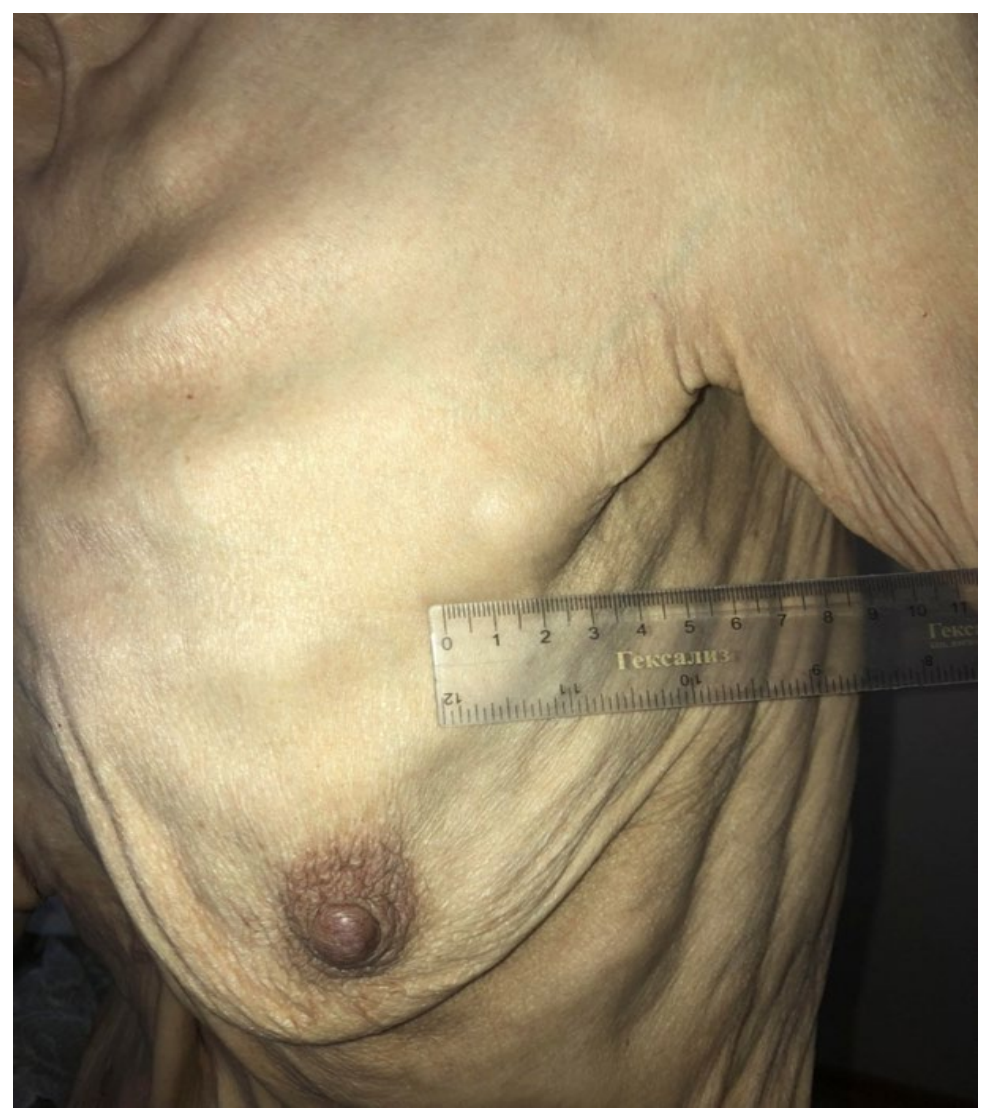

Figure 1: Metastasis to the soft tissues of the left axillary region

with resection of lower third of the thoracic esophagus. Postoperative histological conclusion No.5445/51404-51432 from 12/23/2017. - moderately differentiated adenocarcinoma of the stomach with germination in all layers and invasion of the esophagus, metastases in 8 of 16 lymph nodes of lesser curvature. In the omentum, spleen, tumor growth was not detected. In the esophageal region of the resection, a picture of esophagitis. In dynamics, she was repeatedly hospitalized in the Department of Therapy and Palliative Care of MOPC of Astana with complaints of bile vomiting, nausea, dysphagia, and conservative symptomatic therapy was performed. In recent months, there has been an increase in the formation of lower third of the left thigh, constant pulling pains in the region of formation. The patient is examined by prof. A.K. Makishev. Given the presence of multiple soft tissue tumors, the pain syndrome was examined on an outpatient basis, hospitalized in the Surgery Department No.2 MOPC of Astana.

Status localis: On the inner surface with the transition to the posterior surface of lower third of the left thigh, there is a tumor-like formation of a round shape, about $5 \times 5 \mathrm{~cm}$ in size, of a dense consistency, mobile, the edges are even. The skin over the formation is not changed. In the axillary region on the left along the anterior axillary line in the 3rd intercostal space, a tumor formation is determined (Figure 1), of dense consistency, up to $3.0 \mathrm{~cm}$ in size. In the lumbar region on the right and in the gluteal region on the left (Figures 1 and 2), dense formations up to $3.0 \mathrm{~cm}$ in size, motionless. 


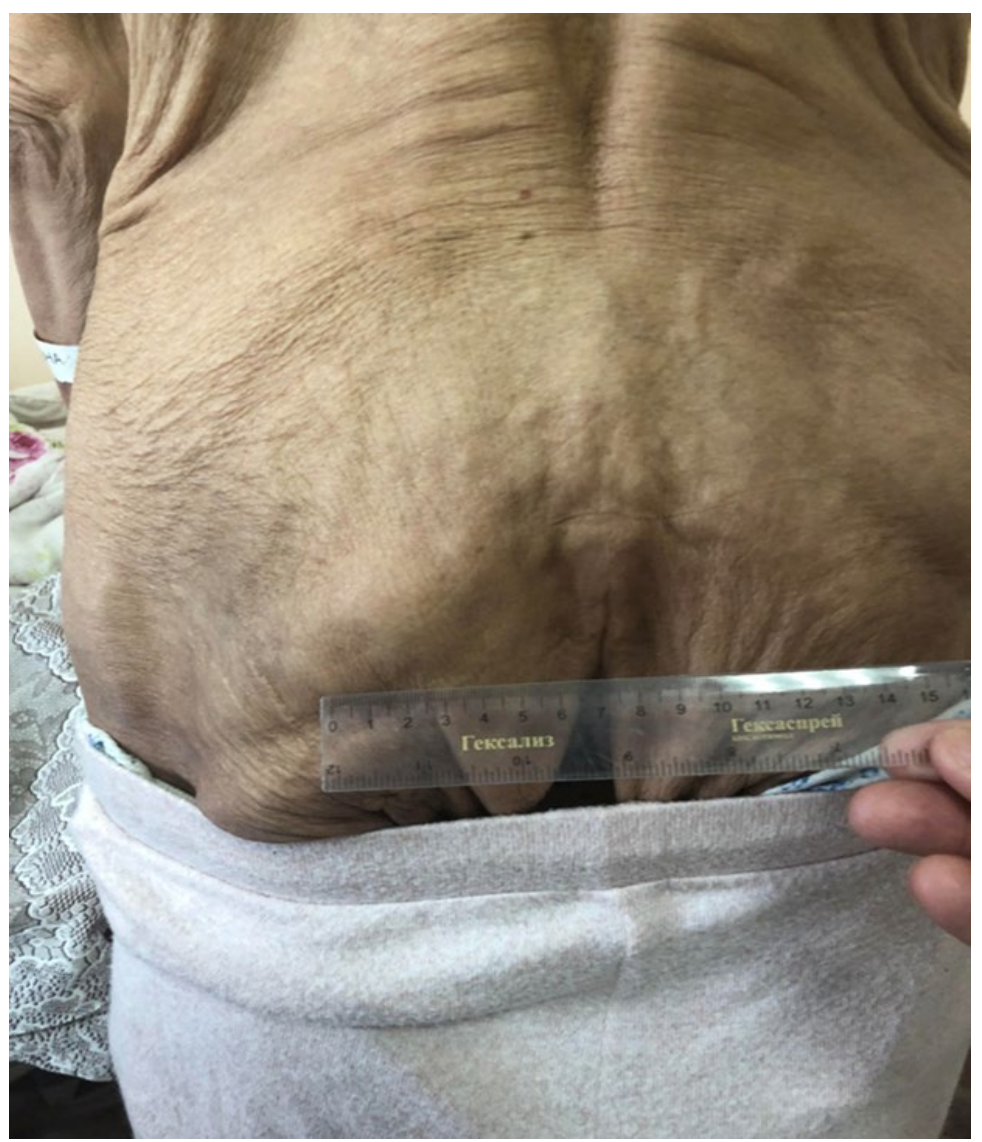

Figure 2: Metastasis in the gluteal region on the left is determined by a dense formation up to $3.0 \mathrm{~cm}$ in size

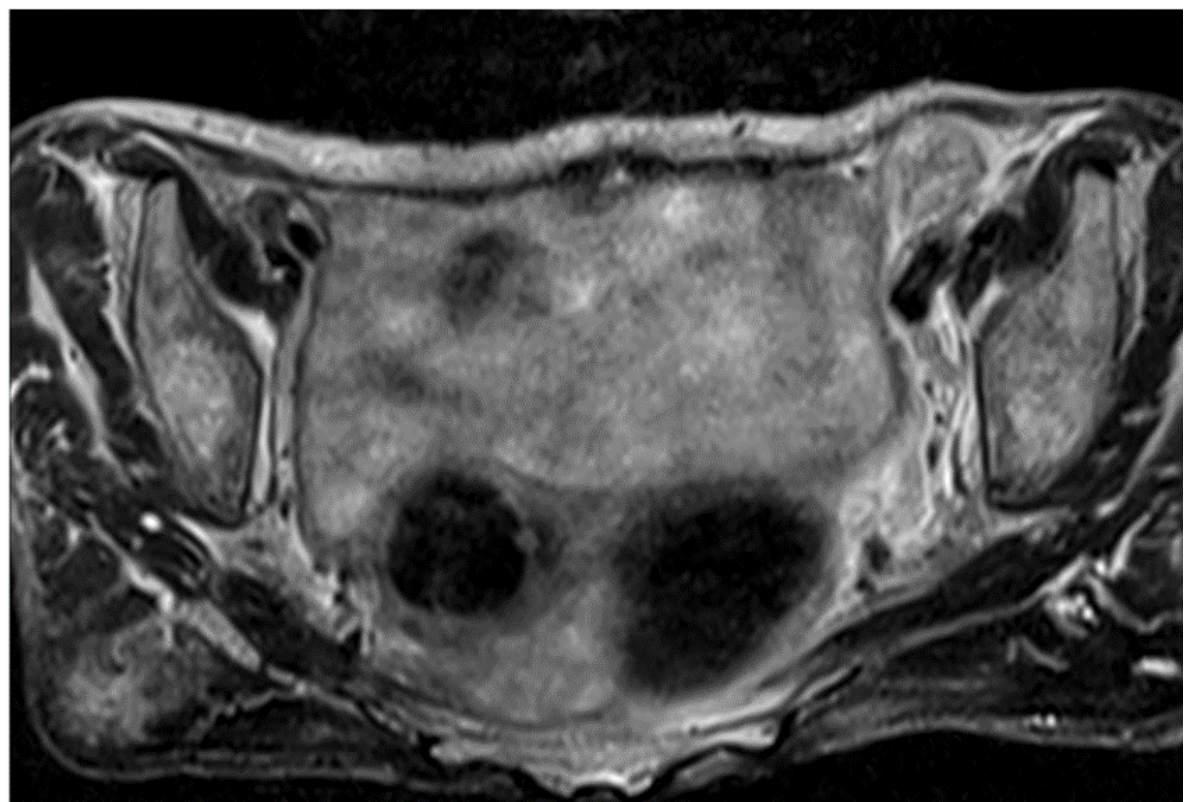

Figure 3: The lymph nodes of inguinal-iliac regions on the left are unevenly enlarged in size $3.2 \times 1.9 \mathrm{~cm}$. Conclusion: MRpicture of the left-side inguinal-iliac lymphadenopathy (MRT of pelvic organs from 09/26/2018)

\section{Examinations}

MRT of the pelvic organs from 09/26/2018: The uterine body with a clear uneven contour, is enlarged in size, the structure is heterogeneous due to a solitary, intramural homogeneous, oval, myomatous, nodular formation of the anterior wall of the uterine body with a clear, even contour $3.4 * 3.2 \mathrm{~cm}$ in size. The lymph nodes of the inguinal-iliac regions on the left are unevenly enlarged in size $3.2 * 1.9 \mathrm{~cm}$ - Figures No.15, No.16. Conclusion: MR picture of left-side inguinal-iliac lymphadenopathy (Figure 3). 


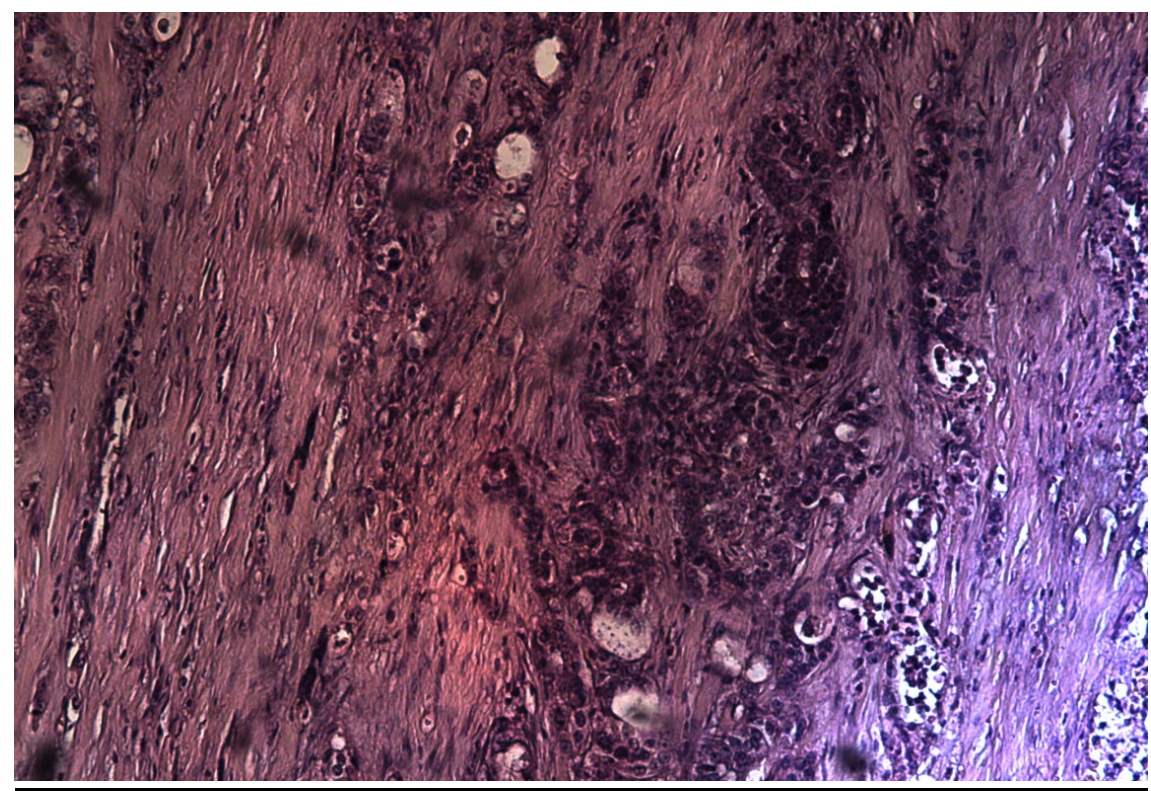

Figure 4: Hematoxylin-eosin stain (magnification x 100). The histological conclusion No.3914/39087-39104 from 09/24/2018: Metastasis of adenocarcinoma in the thickness of muscle tissue

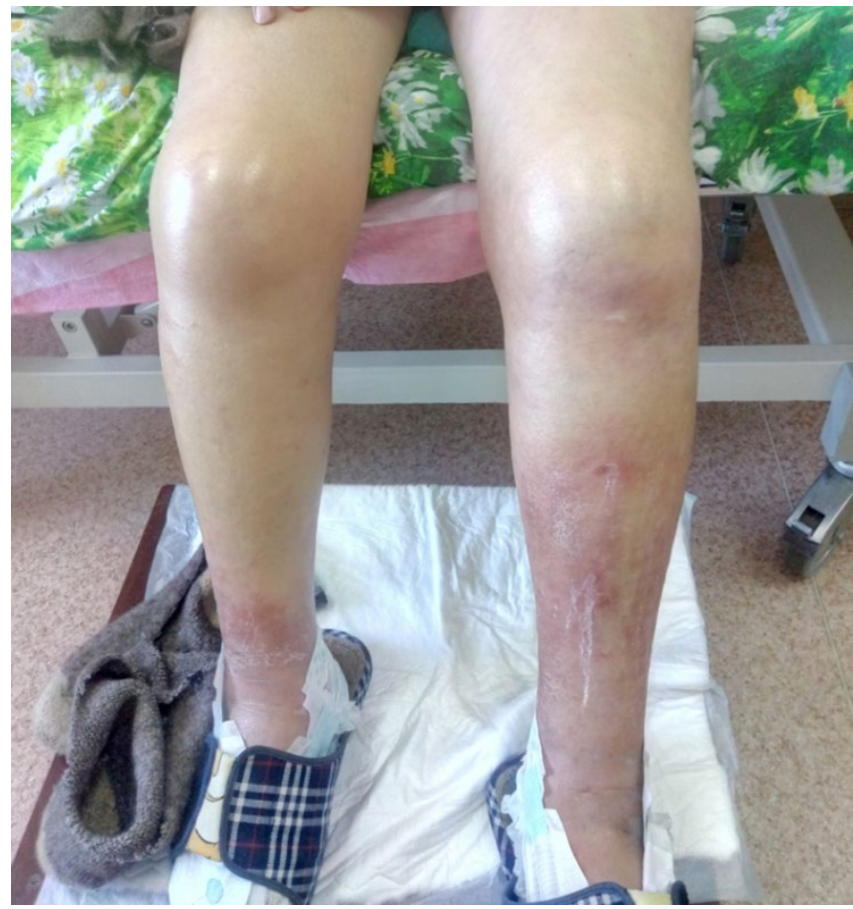

Figure 5: General view of the lower extremities

OPERATION from 09/19/2018: Removal of soft tissue formations of lower third of the left thigh, left gluteus, left axillary regions (Prof. A.K. Makishev)

HISTOLOGICAL CONCLUSION No.3914/39087-39104 from 09.24.2018: metastases of adenocarcinoma in the thickness of muscle tissue (Figure 4).

Further, the patient is directed to symptomatic treatment at the place of residence.

03/12/2019 at the next hospitalization, the patient has marked edema on the legs (more on the left), pain, asthenovegetative syndromes.

Condition on admission: General condition is relatively satisfactory. In the region of previous surgical interventions, there is no data for relapse (left axillary, left gluteus, left popliteal region, postoperative laparotomy scar).

Status localis: pronounced edema on the legs, lymphorrhea, there is hyperemia of the left lower leg skin, skin of the right ankle joint (regarded as erysipelas, antibiotic therapy was carried out), ulceration up to $1 \mathrm{~cm}$ in size, contact blood (Figure 5). 


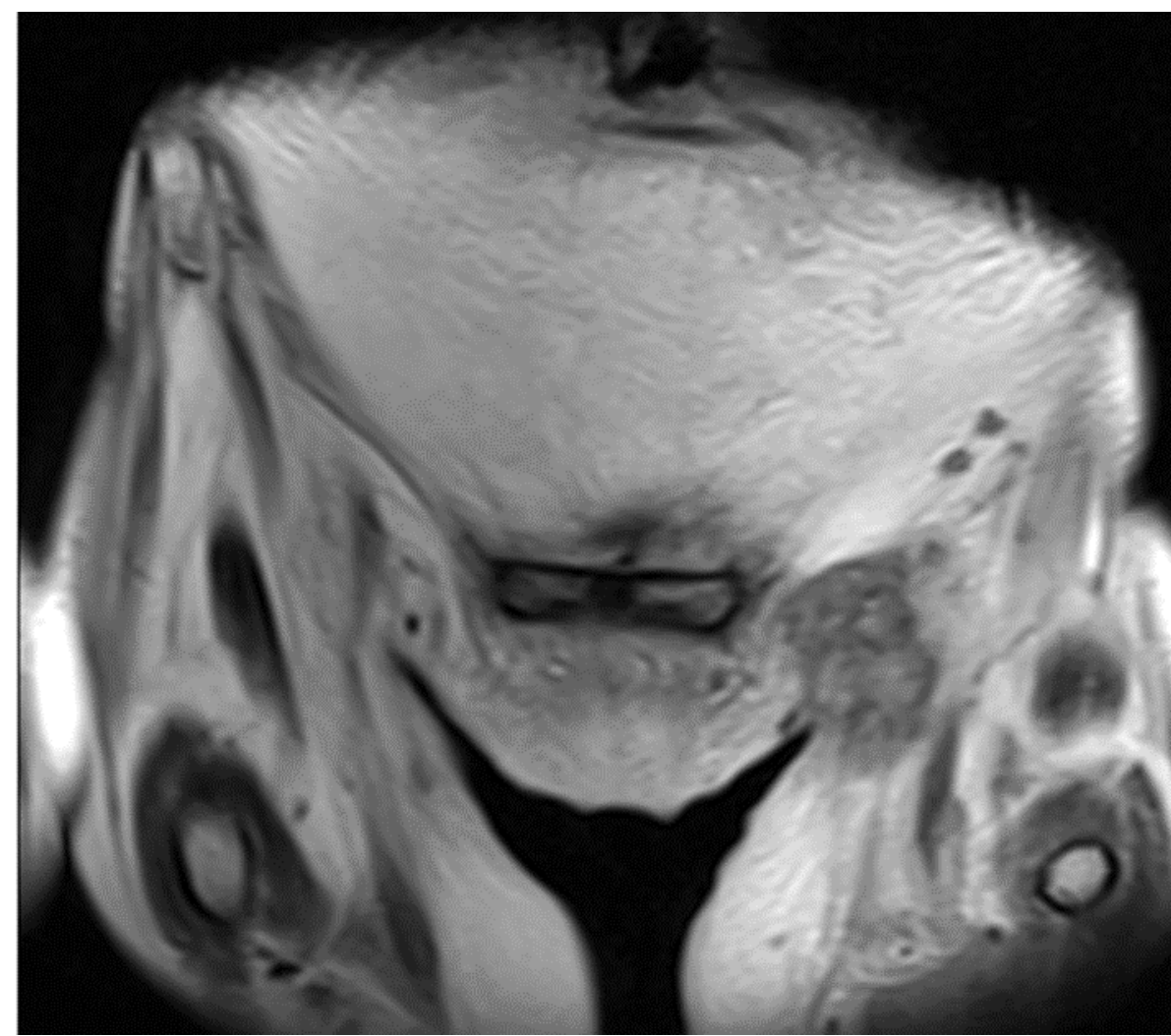

Figure 6: MR-picture of pronounced left-sided inguinal lymphadenopathy (mts), (MRT of pelvic organs from 03.15.2019)

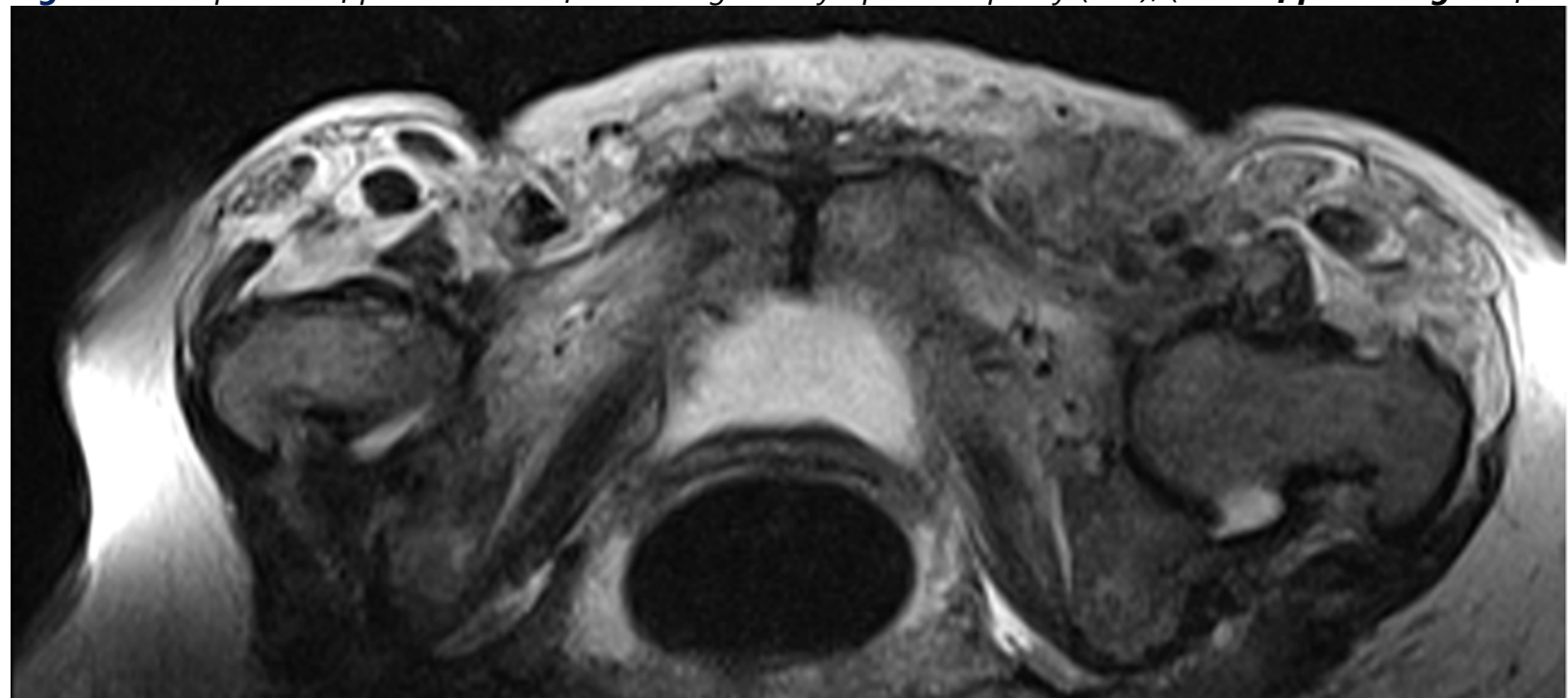

Figure 7: MR-picture of pronounced left-sided inguinal lymphadenopathy (mts), (MRT of pelvic organs from 03.15.2019)

Also, taking into account NMR tomography data of pelvic organs from 09/26/2018, 03/15/19, an ultrasound scan and NMR tomography data of pelvic organs were performed: ... The lymph nodes of the inguinal-iliac regions on the left are unevenly enlarged with a size of $5.0 \times 3.2 \mathrm{~cm}$. Conclusion: MR picture of a pronounced left-side inguinal-iliac lymphadenopathy (mts) (Figures 6 and 7 ).

Infusion, diuretic, antibacterial therapy, parenteral nutrition, drugs that improve microcirculation were given to patient.

Trephine-biopsy of the left inguinal lymph nodes was performed. The histological conclusion of 03/18/19, No.1163/10648-10649: Metastasis of adenocarcinoma in the thickness of fibrous tissue (Figure 8). 


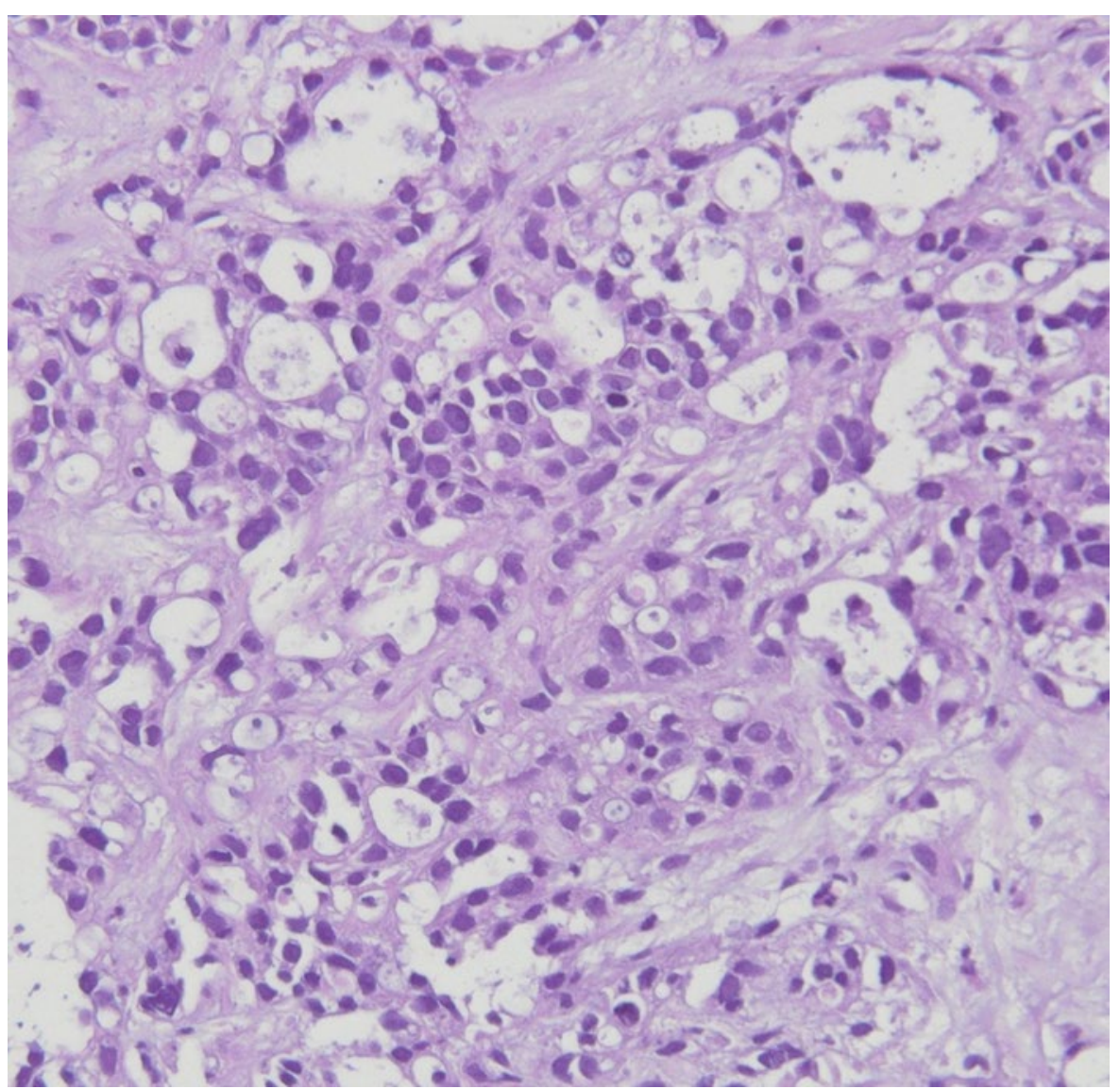

Figure 8: Hematoxylin-eosin stain (magnification $x$ 400). The histological conclusion from 03/18/19, No.1163/1064810649: Metastasis of adenocarcinoma in the thickness of fibrous tissue

Despite the ongoing symptomatic therapy in a hospital, a significant improvement in the patient's condition was not observed. 03/20/2019 the patient was discharged for symptomatic treatment at the place of residence.

\section{DISCUSSION}

This clinical case makes it original that there is a fact of metastatic lesion of the inguinal nodes. Since the literature describes cases of lesions of the supraclavicular nodes on the left - Virchow nodes, bilateral ovarian lesions Krukenberg's tumors, metastases in the paraumbilical region - Sister Mary Joseph's nodules, the Irish node - metastasis in the left axillary region, Schnitzler metastasis - in the lymph nodes of the pararectal tissue, a large tumor node in the pelvis, determined by rectal and vaginal examination (Blumer's protrusion) (6). The purpose of the article is to draw the attention of clinician-oncologists and other doctors to the possible metastasis of gastric cancer into completely unexpected groups of lymph nodes and organs that do not fall within the generally accepted classification and, possibly, by publication to attract attention and find other similar cases in order to satisfy the pattern of the indicated metastasis and use these data for tertiary prophylaxis (prevention, early diagnosis and treatment of relapses) (7). It should also be noted that the disease can manifest with metastatic lesions of non-standard groups of lymph nodes and organs, which is important for the diagnosis of gastric cancer, since the primary localization of the oncological process may not manifest itself clinically. The treatment tactics in case of metastatic lesion of the inguinal nodes in gastric cancer is not entirely clear. We think that in the case of a solitary lesion, active surgical tactics are necessary, as is possible, for example, with solitary metastasis to the paraumbilical region (Sister Mary Joseph's nodules) (5), but in the case of a disseminated process, one should be inclined to drug therapy. In this particular case, relapses and complications in the region of distant metastases removal were not observed (left axillary, left popliteal, left gluteal region). In any case, these patients need a multidisciplinary, individual approach in solving further treatment tactics, with no exception to the possible subsequent surgical treatment in case of pain and the risk of subsequent complications (lymphostasis) in order to prevent them. 


\section{ACKNOWLEDGEMENTS}

We would like to separately thank the attending physician F.U. Abdurakhmanov, for the computer and technical (taking pictures) support, as well as the head of the department of therapy and palliative care of SMMC on REM "Oncological Center" of Nur-Sultan, S.K. Kozhagalieva, head of the Department of Oncology, prof. A.K. Makishev for comprehensive general support in writing this article.

\section{REFERENCES}

1. Abramov ME, Bardovskaya KS, Meshcheryakov AA, Medvedeva BM. Disseminated gastric cancer: a case report. Available at: https://lib.medvestnik.ru/articles/Disseminirovannyi-rak-jeludka-opisanie-klinicheskogo-sluchaya. html

2. Sanford M. A Review of Its Use in Advanced Gastric Cancer in Non-Asian Populations. Drugs, 2013;73(8):845-55. https://doi.org/10.1007/s40265-013-0062-y PMid:23719766

3. Protasova AE, Semenova IV, Raskin GA, Mukhina MS, Kuzmina NS, Orlova RV. Metastasis of gastric adenocarcinoma in the uterine body and cervix. Clinical case. Available at: http://www.malignanttumours.org

4. Pyrhonen $S$, Kuitunen $T$, Nyandoto $P$, et al. Randomized comparison of fluorouracil, epidoxorubicin and methotrexate (FEM- TX) plus supportive care with best supportive care alone in patients with non-resectable gastric cancer. $\mathrm{Br} J$ Cancer, 1995;587:91. https://doi.org/10.1038/bjc.1995.114 PMid:7533517 PMCid:PMC2033628

5. Besova NS, Byakhov My, Konstantinova MM, Lyadov VK, Ter-Ovanesov MD, Tryakin AA. Practical recommendations for the medicinal treatment of gastric cancer. Available at: https://rosoncoweb.ru/standarts/RUSSCO/2017/recoms2017_19.pdf

6. Chissov VI, Daryalova SL. Oncology, 2007;65:362.

7. Nikolayev EV. Primary cancer prevention in modern Russia. 2011:6.

$\diamond \diamond \diamond \diamond \diamond \diamond \diamond$

http://www.ejgm.co.uk 